\title{
HT2003-47406
}

\section{TRANSMITTANCE AND RADIANCE COMPUTATIONS FOR ROCKET ENGINE PLUME ENVIRONMENTS}

\author{
Gopal D. Tejwani \\ Lockheed Martin Space Operations \\ Systems Engineering and Advanced Technologies Department \\ John C. Stennis Space Center \\ Stennis Space Center, Mississippi 39529 \\ e-mail: gtejwani@ssc.nasa.gov
}

\section{ABSTRACT}

Rocket engine exhaust plume is generally thermal in character arising from changes in the internal energy of constituent molecules. Radiation from the plume is attenuated in its passage through the atmosphere. In the visible and the infrared region of the spectrum for clear-sky conditions, this is caused mainly through absorption by atmospheric molecular species. The most important combustion-product molecules giving rise to emission in the IR are water vapor, carbon dioxide, and carbon monoxide. In addition, the high temperature plume reacting with the surrounding atmosphere may produce nitrogen oxides, in the boundary layer, all of which are strongly emitting molecules. Important absorbing species in the atmosphere in the engine plume environment are $\mathrm{H}_{2} \mathrm{O}, \mathrm{CO}, \mathrm{CO}_{2}, \mathrm{CH}_{4}, \mathrm{~N}_{2} \mathrm{O}, \mathrm{NO}$, and $\mathrm{NO}_{2}$. Under normal atmospheric conditions, the concentrations of $\mathrm{O}_{3}, \mathrm{SO}_{2}$, and $\mathrm{NH}_{3}$ are too small to produce any significant absorption. Essentially the problem comprises of the propagation of radiation from a hot gas source through a long cool absorbing atmosphere thus combining aspects of atmospheric and combustion gas methods. Since many of the same molecular species are responsible for both emission and absorption, the high degree of line position correlation between the emission and absorption spectra precludes the decoupling of the optical path into isolated emitter and absorber regions and multiplying the source band radiance by the absorber band transmittance in order to arrive at the transmitted radiance spectrum. Also, very strong thermal gradients may be encountered. All this suggests that a layerby-layer computation is called for. The pathlength through the
\end{abstract}

plume and the atmosphere is assumed to go through a certain number of layers, each of which is considered to have all molecular species in local thermodynamic equilibrium at constant temperature and pressure within the layer. Radiative transfer problems can be visualized as a set of parallel layers orthogonal to the line of sight, each with an input radiance from the previous layer and an output radiance to the subsequent layer. The MODTRAN (MODerate resolution TRANsmission) code is ideally suited for layer-by-layer absorption/emission calculations for atmospheric molecular species. We have utilized MODTRAN 4.0 computer code, implemented on a Power Mac G3, for the radiance and transmittance computations. The MODTRAN code has been adapted for the engine plume radiance computations. If the plume composition and flowfield parameters such as the temperature and pressure values are known along the line of sight by means of the experimental measurements or (more likely) CFD simulations, one can compute the radiance from any plume with high degree of accuracy at any desired point in space. Emission and absorption characteristics of several atmospheric and combustion species have been studied and presented in this paper with reference to the rocket engine plume environments at the Stennis Space Center. In general transmittance losses can not be neglected for any pathlength of $2 \mathrm{~m}$ or more. We have also studied the effect of clouds, rain, and fog on the plume radiance/transmittance. The transmittance losses are severe if any of these occur along the line of sight. Preliminary results for the radiance from the exhaust plume of the space shuttle main engine are shown and discussed. 
Keywords: Transmittance, Plume Radiance, MODTRAN, Rocket Engine Plume

\section{NOMENCLATURE}

$A_{V}$ monochromatic absorption

$E^{\prime \prime}$ energy of the lower state

$Q_{r} \quad$ rotational partition function

$Q_{v} \quad$ vibrational partition function

$S$ line intensity per absorbing molecule

$T$ temperature, $\mathrm{K}$

$k \quad$ spectral absorption coefficient

$m$ absorbing material amount

$\gamma_{o} \quad$ line half-width at half-maximum

$\delta L$ differential increase in pathlength

$\mu$ wavelength

$v$ frequency

$\mathrm{v}_{o}$ resonant frequency

\section{INTRODUCTION}

John C. Stennis Space Center (SSC) is NASA's designated Center of Excellence for large rocket propulsion testing. Radiant-energy transfer is of fundamental importance in the understanding and in the solution of many engineering problems in the SSC's rocket engine testing environments. Examples of interesting practical applications are theoretical calculations of radiant heat transfer for plume-induced environments, plume temperature measurements, and spectroscopic analysis of multi component gas mixtures for the engine health monitoring and for the EPA compliance. Rocket exhaust plume is generally thermal in character, arising from changes in the internal energy of constituent molecules. Radiation from the plume is attenuated in its passage through the atmosphere. In the visible and the infrared region of the spectrum for clear-sky conditions, this is caused mainly through absorption by atmospheric molecular species.

Rocket engines are tested at SSC for improvement, development and flight certification. Although, the Space Shuttle Main Engine (SSME) is the most famous of rocket engines currently being tested at SSC, several types of hydrocarbon fuel rocket engines have also been or currently being tested at SSC. High temperature exhaust plume is responsible for very strong IR emissions due to combustion-product molecules, water vapor, carbon dioxide, and carbon monoxide. In addition, the high temperature plume reacting with the surrounding atmosphere may produce nitrogen oxides, in the boundary layer, all of which are strongly emitting molecules. Important absorbing species in the atmosphere in the engine plume environment are $\mathrm{H}_{2} \mathrm{O}, \mathrm{CO}, \mathrm{CO}_{2}$, $\mathrm{CH}_{4}, \mathrm{~N}_{2} \mathrm{O}, \mathrm{NO}$, and $\mathrm{NO}_{2}$. Under normal atmospheric conditions, the concentrations of $\mathrm{O}_{3}, \mathrm{SO}_{2}$, and $\mathrm{NH}_{3}$ are too small to produce any significant absorption. Essentially the problem comprises of the propagation of radiation from a hot gas source through a long cool absorbing atmosphere thus combining aspects of atmospheric and combustion gas methods. Since many of the same molecular species are responsible for both emission and absorption, the high degree of line position correlation between the emission and absorption spectra precludes the decoupling of the optical path into isolated emitter and absorber regions and multiplying the source band radiance by the absorber band transmittance in order to arrive at the transmitted radiance spectrum. Also, very strong thermal gradients may be encountered. All this suggests that a layer-by-layer computation is called for. The pathlength through the plume and the atmosphere is assumed to go through a certain number of layers, each of which is considered to have all molecular species in local thermodynamic equilibrium at constant temperature and pressure within the layer. Radiative transfer problems can be visualized as a set of parallel layers orthogonal to the line of sight, each with an input radiance from the previous layer and an output radiance to the subsequent layer. The MODTRAN (MODerate resolution TRANsmission) code is ideally suited for layer-by-layer absorption/emission calculations for atmospheric molecular species. We have utilized MODTRAN 4.0 computer code, implemented on a Power Mac $\mathrm{G} 3$, for the radiance and transmittance computations. A brief description of the main features of the code is given in the next Section followed by some theoretical background. Transmittance computations and results are discussed. The MODTRAN code has been adapted for the engine plume radiance computations. The SSME radiance computations and results are shown. For both transmittance as well as radiance computations, parametric studies with respect to the concentration of the relevant molecular species and the pathlength have been performed.

\section{MODTRAN PROGRAM}

MODTRAN is a moderate resolution model and computer code for predicting atmospheric transmittance and background radiance in the microwave, infrared, visible and near ultraviolet spectral regions for any given atmospheric path. This code has evolved from the LOWTRAN (LOW resolution TRANsmission) codes, with LOWTRAN 7 being the last and the most current version [1]. Its spectral resolution is $20 \mathrm{~cm}^{-1}$ Full Width/Half Maximum (FWHM) with calculations being done in $5 \mathrm{~cm}^{-1}$ increments. MODTRAN increases LOWTRAN's spectral resolution from 20 to $2 \mathrm{~cm}^{-1}$ (FWHM). It models molecular absorption of twelve atmospheric species as a function of temperature and pressure. Molecular absorption is calculated in 1 $\mathrm{cm}^{-1}$ spectral bins. The MODTRAN band model uses three temperature-dependent parameters, an absorption coefficient, a line density parameter and an average linewidth. The twelve molecular species are water vapor, carbon dioxide, ozone, nitrous oxide, carbon monoxide, methane, oxygen, nitric oxide, sulfur dioxide, nitrogen dioxide, ammonia and nitric acid. Their 
absorption properties (the band model parameters) are calculated from the HITRAN line atlas [2], which contains all lines in the $0-17,900 \mathrm{~cm}^{-1}$ spectral region that have significant absorption for atmospheric paths. Further details of the code are available in Ref. [3]. We have implemented MODTRAN 4.0 computer code on a Power Mac G3.

\section{THEORETICAL BACKGROUND}

The theoretical foundations for the radiance and the atmospheric transmittance computations are available in two pioneering books by Penner [4] and Goody [5]. The main equation of radiative transfer, although complex, can be summarized in a single integro-differential equation in terms of physical parameters pertinent to the particular problem of radiative transfer. For the atmosphere, these parameters are represented by factors like meteorological quantities, atmospheric constituents, specific sources of radiation within or external to the atmosphere, geometrical configurations of sources, and the detectors of radiation. Taking into account all these factors and assuming that the earth's atmosphere can be considered as made up of plane layers parallel to an essentially plane earth surface, a complete set of equations is available in Ref. [5] for different approaches or methods of calculating atmospheric transmittance and radiance. The most accurate method is line-by-line calculation. It is based on a set of line spectral parameters that describe the molecular lines in which radiation is absorbed or emitted. However, even for a narrow spectral range, thousands of molecular lines need to be considered. Therefore, routine transmittance computations are not feasible to be carried out by utilizing the line-by-line approach. The preferred methodology for these computations is based on band-models [5] at tremendous reduction in computational resources without too much sacrifice in accuracy. LOWTRAN and MODTRAN computer codes utilize band model approach. Earlier versions of the LOWTRAN computer code manuals [6] give detailed equations for the radiance and the transmittance calculations using band model methodology. These equations will not be repeated here as the complete set of equations is very extensive. However, it would be instructive to describe the absorption process for a single molecular transition or line. The four essential line parameters for each line are the resonant frequency, $v_{o}$, the intensity per absorbing molecule, $S$, the Lorentz line width parameter, $\gamma_{o}$, and the energy of the lower state, $E^{\prime \prime}$. The spectral absorption coefficient for the Lorentz line shape is:

$$
\begin{gathered}
k(v)=\frac{S \gamma_{o}}{\pi\left(v-v_{o}\right)^{2}+\gamma_{o}^{2}} \\
S=\int k(v) d v
\end{gathered}
$$

The line half-width at half-maximum, $\gamma_{o}$, is by definition proportional to the pressure, $p$, and its temperature dependence can be computed for each transition of every molecular specie [7]. The line intensity is temperature dependent through the Boltzmann factor and the partition function as indicated in Eq. (3),

$$
S(T)=\frac{S\left(T_{s}\right) Q_{v}\left(T_{S}\right) Q_{r}\left(T_{s}\right)}{Q_{v}(T) Q_{r}(T)} \exp \left[\frac{1.439 E^{\prime \prime}\left(T-T_{s}\right)}{T T_{s}}\right]
$$

where $Q_{v}$ and $Q_{r}$ are the vibrational and rotational partition functions. $T_{S}$ is standard atmospheric temperature, taken to be $296 \mathrm{~K}$ in all spectral line parameter compilations. For a homogeneous path, the monochromatic absorption at a frequency $v$ is obtained from

$$
A_{\mathrm{v}}=1-T_{\mathrm{v}}=1-\exp \left(-k_{\mathrm{v}} m\right)
$$

where $T_{v}$ is the monochromatic transmission and $m$ is the amount of absorbing material.

As mentioned earlier, the MODTRAN computer code utilizes the complete band model parameters for $\mathrm{H}_{2} \mathrm{O}, \mathrm{CO}_{2}, \mathrm{O}_{3}$, $\mathrm{N}_{2} \mathrm{O}, \mathrm{CO}, \mathrm{CH}_{4}, \mathrm{O}_{2}, \mathrm{NO}, \mathrm{SO}_{2}, \mathrm{NO}_{2}, \mathrm{NH}_{3}$, and $\mathrm{HNO}_{3}$. In addition, heavy species, which include nine chlorofluorocarbons (CFC's) plus $\mathrm{C} \ell \mathrm{ONO}_{2}, \mathrm{HNO}_{4}, \mathrm{CC}_{4}$, and $\mathrm{N}_{2} \mathrm{O}_{5}$ have been added recently. However, the band model parameters for heavy species are not as accurate, extensive, or complete as the twelve main constituents.

MODTRAN code has the feature of utilizing one of the six geographical - seasonal model atmospheres or it can read userdefined meteorological or radiosonde data. The model atmospheres correspond to the 1962 U.S. Standard atmosphere, and the five supplementary models: that is, Tropical $\left(15^{\circ} \mathrm{N}\right)$, Mid latitude Summer $\left(45^{\circ} \mathrm{N}\right.$, July), Mid latitude Winter $\left(45^{\circ} \mathrm{N}\right.$, January), Subarctic Summer $\left(60^{\circ} \mathrm{N}\right.$, July), and Subarctic Winter $\left(60^{\circ} \mathrm{N}\right.$, January). Obviously, none of these models are going to provide a very good representation of the atmospheric conditions at the SSC. However, since we aim to do a parametric study of the transmittance and radiance with respect to the species concentrations and since we are mostly interested in relatively small pathlengths (100 m maximum), Mid latitude Summer model will provide more than adequate starting point for this study. Complete details of the input files including the model atmospheres are available in Ref. [3].

\section{TRANSMITTANCE COMPUTATIONS AND RESULTS}

Transmittance computations have been performed for the spectral range of 0.4 to $20.0 \mu$. This region encompasses blackbody curves for the temperature range of interest (300 to $3200 \mathrm{~K}$ ) 
for the engine testing plume environment. As mentioned earlier, most of our computations have been performed by utilizing mid latitude summer Model. Three other Model atmospheres were tried, namely, U. S. Standard atmosphere, tropical, and mid latitude winter. The average transmittance for $100 \mathrm{~m}$ pathlength was computed to be $0.917,0.888,0.928$, and 0.897 for U. S. Standard atmosphere, tropical, mid latitude winter, mid latitude summer models, respectively.

Figure 1a shows the total transmittance (or absorbance) along with absorbance due to the water vapor and water vapor continuum for $100 \mathrm{~m}$ pathlength in the spectral range of 0.4 to $20.0 \mu . \mathrm{H}_{2} \mathrm{O}$ has strong absorption due to two fundamental bands $v_{3}$ and $v_{2}$ centered at 2.66 and $6.27 \mu$, respectively. In addition, $v_{1}$ fundamental (band center at $2.74 \mu$ ) and several overtone and combination bands are responsible for absorption from 0.4 to $3.5 \mu$. The water vapor absorption from 10.0 to $20.0 \mu$ is due to the pure rotational band [8]. For water vapor, the absorption measured in the laboratory or in the atmosphere is usually greater than that predicted on the basis of known positions, intensities and widths of the lines and previously adopted theoretical line shapes. The excess absorption that represents the difference between the experimental and calculated values is referred as the continuum absorption because it does not change rapidly with changing wavenumber. The continuum absorption is mostly attributed to absorption by dimers consisting of 2 bound $\mathrm{H}_{2} \mathrm{O}$ molecules or by clusters of several molecules. Water vapor continuum absorption model is based on LOWTRAN 6 [6]. CO, $\mathrm{CO}_{2}$ and $\mathrm{CO}_{2}^{+}$absorption is shown in Fig. 1b. Total transmittance is also shown for comparison. Concentration of $\mathrm{CO}_{2}$ has been taken to be 360 ppmv instead of using the default value of 330 ppmv for the mixing ratio as $\mathrm{CO}_{2}$ concentration in the atmosphere has been steadily increasing [3]. $\mathrm{CO}_{2}$ and $\mathrm{CO}_{2}^{+}$have very strong absorption bands at 4.26 and $14.98 \mu$ corresponding to $v_{3}$ and $v_{2}$ fundamental bands, respectively. $v_{1}$ fundamental band is inactive in the infrared. The absorption at $2.69 \mu$ is due to the $v_{1}+v_{3}$ combination band. $\mathrm{CO}$ has a strong fundamental band at $4.67 \mu$ and moderately strong first overtone band at $2.33 \mu$. However, $\mathrm{CO}$ concentration (roughly $0.07 \mathrm{ppmv}$ ) in the normal atmosphere is too small for these and other bands of $\mathrm{CO}$ to impact the transmittance very significantly. For normal atmospheric concentrations of $\mathrm{N}_{2} \mathrm{O}$, fundamental bands $v_{1}, v_{2}$, and $v_{3}$ absorb noticeably at $4.50,16.98$, and $7.78 \mu$, respectively and $\mathrm{CH}_{4}$ has active and strong fundamental bands at 3.31, 3.46, and $7.66 \mu$ corresponding to $v_{3}, v_{1}$, and $v_{4}$ [9]. For the sake of brevity, $\mathrm{N}_{2} \mathrm{O}$ and $\mathrm{CH}_{4}$ absorptions are not shown here. However these plots are available in Ref. [10]. Contribution from other species such as $\mathrm{O}_{3}, \mathrm{NH}_{3}, \mathrm{NO}, \mathrm{NO}_{2}$, and $\mathrm{HNO}_{3}$ are not shown because their concentration is too small in the normal atmosphere at or near the ground level for significant absorption to occur at rather small pathlength of $100 \mathrm{~m}$.

The effect of the pathlength on the total transmittance can be seen in Fig. 2 where the results for the pathlengths of 1, 5, and
$100 \mathrm{~m}$ are shown. The average transmittance for 1, 2, 5, 20, and $100 \mathrm{~m}$ is $0.987,0.981,0.969,0.943$, and 0.897 , respectively.

We have performed parametric studies of transmittance vs. concentration for many species which are present in the plume under various engine firings. For example, $\mathrm{CO}$ and $\mathrm{CO}_{2}$ in addition to $\mathrm{H}_{2} \mathrm{O}$ are the main combustion products during hydrocarbon-fueled rocket engine testing. Elevated levels of various nitrogen oxides $\left(\mathrm{NO}, \mathrm{N}_{2} \mathrm{O}\right.$, and $\left.\mathrm{NO}_{2}\right)$ are generated in the mixing layer between the plume and the surrounding atmosphere. Parametric studies have been performed for $\mathrm{H}_{2} \mathrm{O}, \mathrm{CO}_{2}$, $\mathrm{CO}, \mathrm{CH}_{4}, \mathrm{~N}_{2} \mathrm{O}, \mathrm{NO}$, and $\mathrm{NO}_{2}$. Any one of these strongly absorbing species affects the transmittance significantly if it is present in the environment at concentrations higher than $200 \mathrm{ppm}$. The actual transmittance computations for any given engine testing environment can be performed if the molecular species distribution along the pathlength can be ascertained by CFD prediction or by prior on-site measurements of species concentrations from a previous test. Also temperature and pressure variations along the pathlength can be taken into account by utilizing appropriate layers perpendicular to the pathlength. For the sake of brevity, we will only show here the results for the $\mathrm{CO}_{2}$ parametric study. Transmittance values for 0.4 to $20 \mu$ for 360, 1000, 5000 and $10,000 \mathrm{ppm}$ are shown in Fig. 3. Because of the saturation of several bands, the increase in absorption is less and less pronounced as the $\mathrm{CO}_{2}$ concentration increases.

Scattering computations in MODTRAN are modeled same as in LOWTRAN 6 [6]. For the most part, under a clear sky conditions, the scattering effects are insignificant. However, under foggy or rainy conditions, scattering becomes the most significant contributor to the transmission losses. This can be seen in Fig. 4 where the total, $\mathrm{H}_{2} \mathrm{O}$ continuum, $\mathrm{H}_{2} \mathrm{O}$, and aerosol transmittance have been plotted for 0.4 to $20 \mu$ for $5.0 \mathrm{~mm} / \mathrm{hr}$ ground light rain. The average total transmittance for this light rain model is 0.063 . We have also studied the effect of moderate rain rate $(12.5 \mathrm{~mm} / \mathrm{hr})$ and very light rain rate or drizzle $(2.0$ $\mathrm{mm} / \mathrm{hr}$ ). The average transmittance is 0.059 and 0.852 for the moderate rain model and for the ground drizzle model, respectively.

We have considered two cases of foggy conditions: advective fog with a visibility of $0.2 \mathrm{~km}$ and radiative fog with a visibility of $0.5 \mathrm{~km}$. Transmission losses are much more severe for advective fog model because of much higher scattering effects from condensed water particles. Figure 5 shows the results for radiative fog, where the total, $\mathrm{H}_{2} \mathrm{O}$ continuum, $\mathrm{H}_{2} \mathrm{O}$, and aerosol transmittance has been plotted for the spectral range of 0.4 to $20.0 \mu$. The average transmittance for radiative fog is $0.409 \mathrm{com}-$ pared to the average transmittance of 0.126 for advective fog.

\section{RADIANCE COMPUTATIONS AND RESULTS}

MODTRAN code is mainly designed and developed for the atmospheric radiance and transmittance computations. As men- 


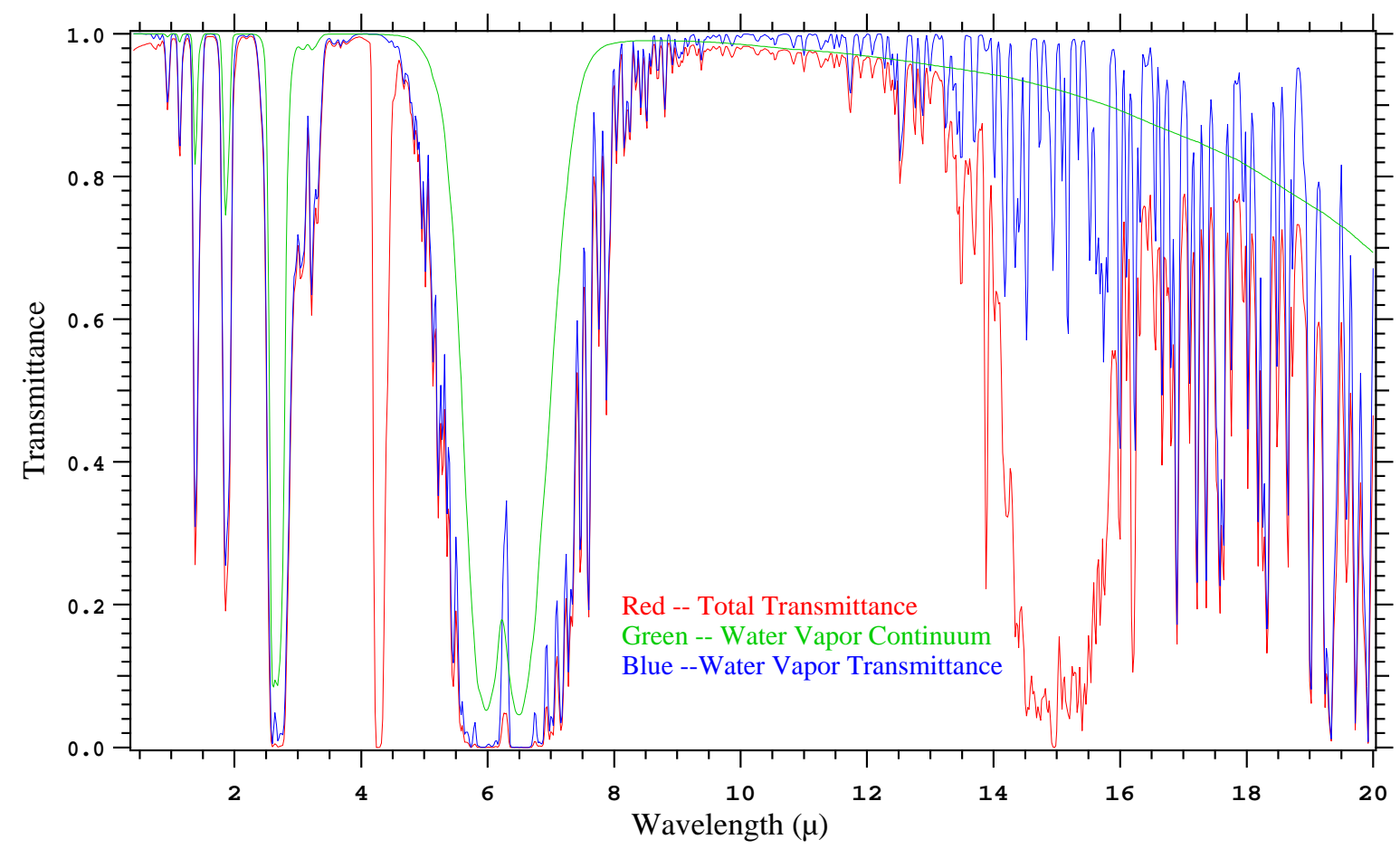

Figure 1a. Total, $\mathrm{H}_{2} \mathrm{O}$ Continuum, and $\mathrm{H}_{2} \mathrm{O}$ Transmittance for 0.4 to $20 \mu$ for $100 \mathrm{~m}$ Pathlength Utilizing Mid-Latitude Summer Model Atmosphere.

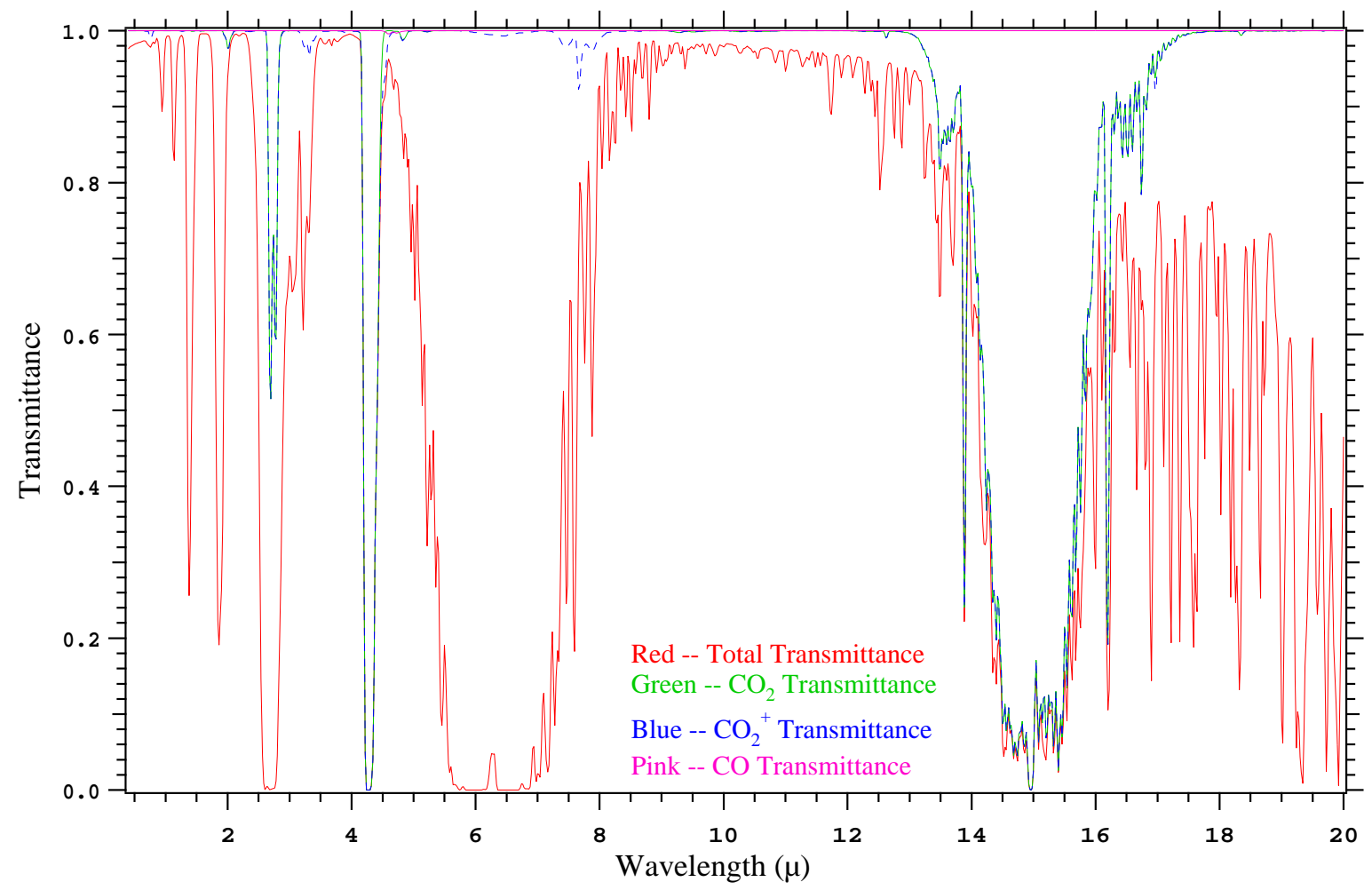

Figure $1 \mathrm{~b}$. Total, $\mathrm{CO}_{2}, \mathrm{CO}_{2}^{+}$, and $\mathrm{CO}$ Transmittance for 0.4 to $20 \mu$ for $100 \mathrm{~m}$ Pathlength Utilizing Mid-Latitude Summer Model Atmosphere. 


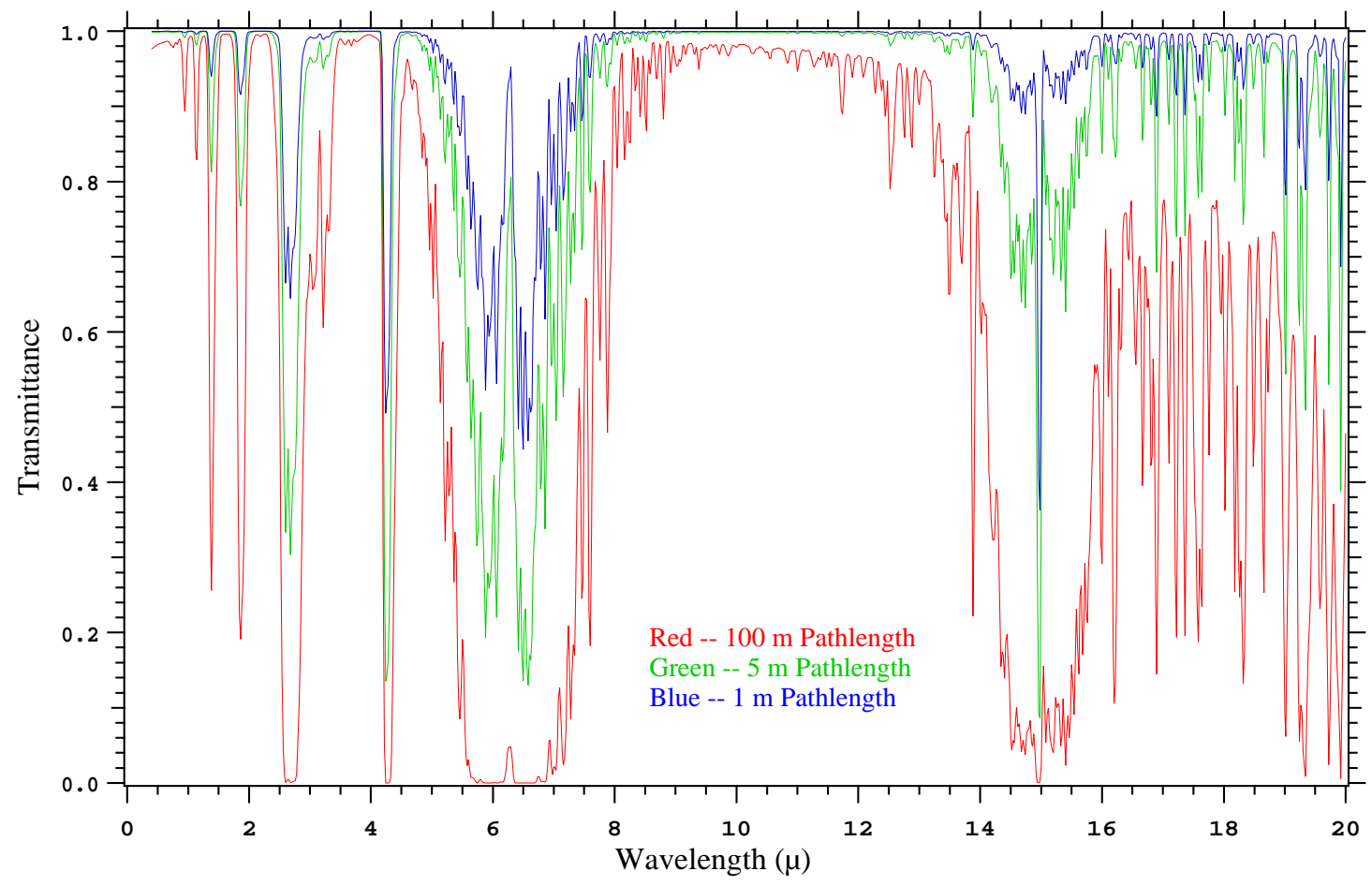

Figure 2. Total Transmittance for 0.4 to $20 \mu$ for 100,5 , and $1 \mathrm{~m}$ Pathlength Utilizing Mid-Latitude Summer Model Atmosphere.

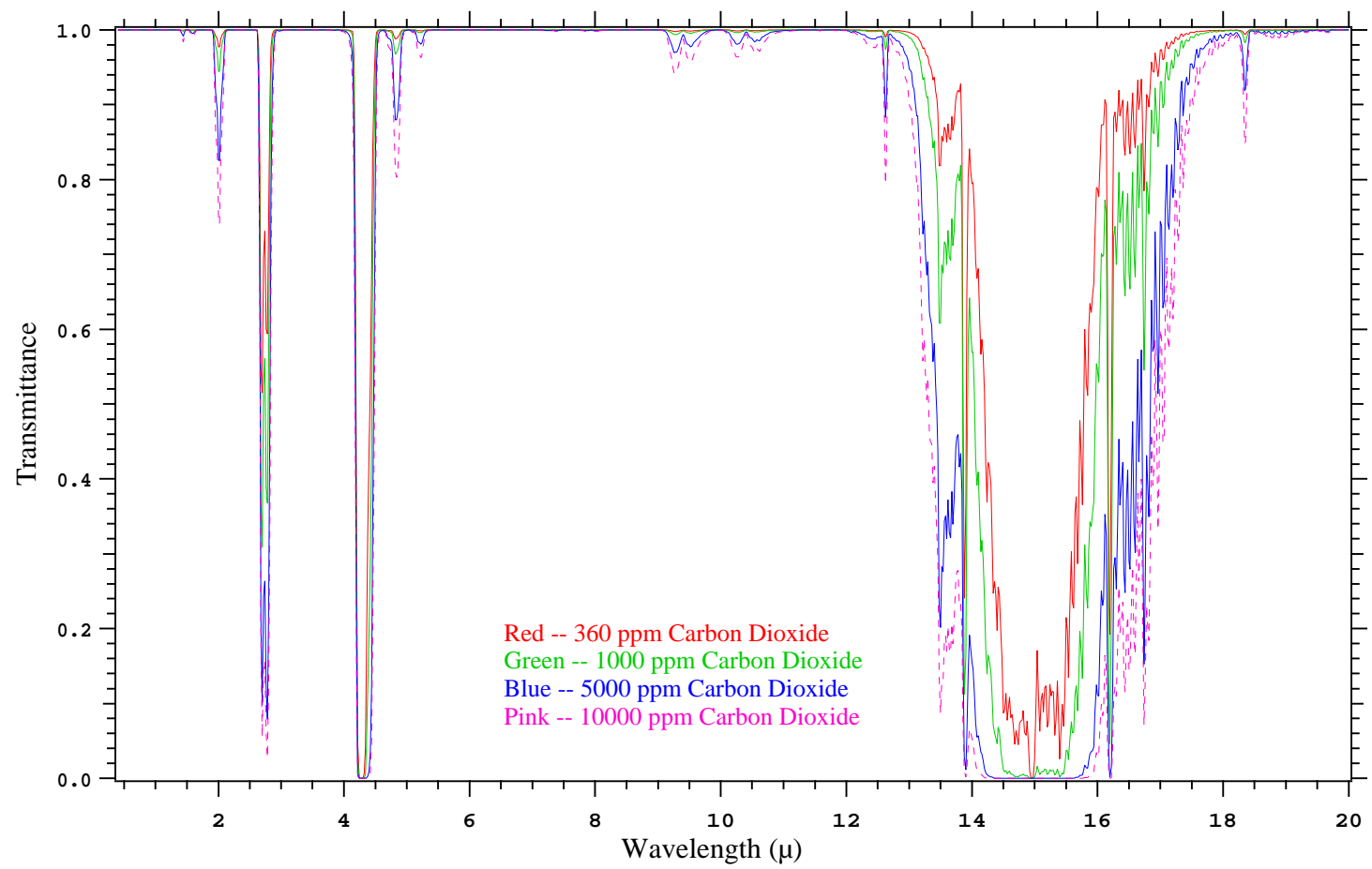

Figure 3. $\mathrm{CO}_{2}$ Transmittance for 0.4 to $20 \mu$ for 360, 1000, 5000, and 10000 ppm Carbon Dioxide and $100 \mathrm{~m}$ Pathlength Utilizing Mid-Latitude Summer Model Atmosphere. 


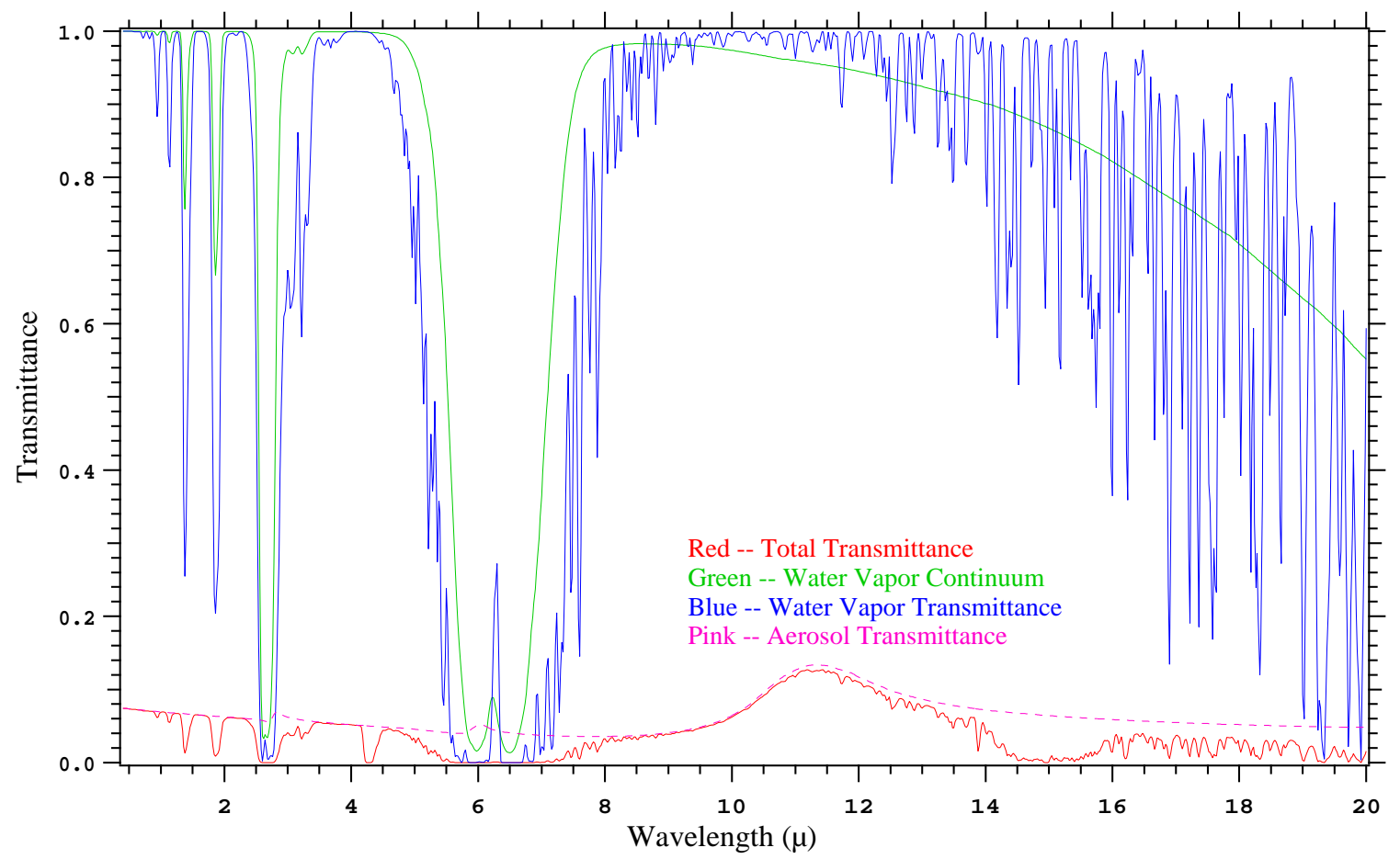

Figure 4. Total, $\mathrm{H}_{2} \mathrm{O}$ Continuum, $\mathrm{H}_{2} \mathrm{O}$, and Aerosol Transmittance for 0.4 to $20 \mu$ for $5.0 \mathrm{~mm} / \mathrm{hr}$ Ground Light Rain and $100 \mathrm{~m}$ Pathlength Utilizing Mid-Latitude Summer Model Atmosphere.

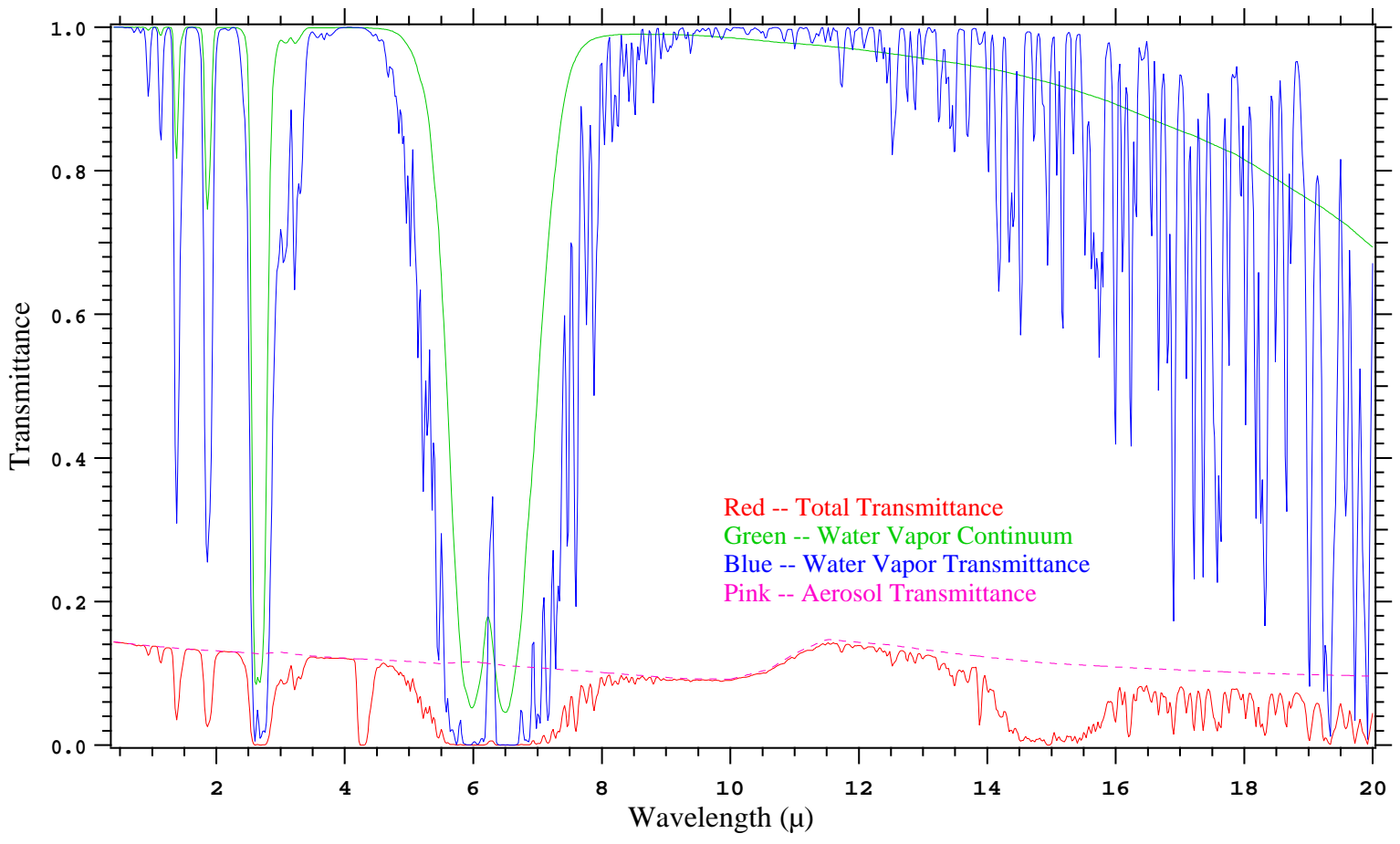

Figure 5. Total, $\mathrm{H}_{2} \mathrm{O}$ Continuum, $\mathrm{H}_{2} \mathrm{O}$, and Aerosol Transmittance for 0.4 to $20 \mu$ for Advective Fog and $100 \mathrm{~m}$ Pathlength Utilizing Mid-Latitude Summer Model Atmosphere. 
tioned earlier, it uses a layer-by-layer approach, where each layer parallel to the surface of the earth can be treated as a horizontal layer in the vicinity of the engine test stand. For the plume radiance computations, we are generally interested in a short line of sight within the first atmospheric layer above the ground. We will simplify the discussion by assuming horizontal or nearly horizontal line of sight. If we locate the high temperature engine plume within the same atmospheric layer, we are faced with the temperature incompatibility problem since by definition each layer consists of constant, uniform thermodynamic properties. This problem was resolved with the help of a NASA summer intern [11]. We assumed a vertical line of sight which allowed us to create a number of thin layers perpendicular to the line of sight within the plume and additional layers of larger width into the atmosphere. For SSME plume, for a line of sight passing through the Mach diamond, it can be approximated by three parallel isothermal layers based on the CFD results for the plume [12]. For this work, we utilized recent CFD results obtained by J. West [13]. Essentially, the first three layers in MODTRAN computations model the plume. The composition of these three layers and other flowfield properties are based on the CFD results. The details of the atmospheric layers and the three layers modeling the plume are given in Ref. [11]. Obviously, in this approach one has to read in all the atmospheric parameter data for all the layers instead of using the default values from the Model atmospheres. The required parameters include the altitude, the pressure, the temperature and the concentration of individual molecular species (total 33 species) at each layer boundary. We have considered only the radiance from the plume. The radiance from the engine and the test stand structural materials have been neglected.

The total radiance for 0.4 to $8.0 \mu$ for 2,5 , and $10 \mathrm{~m}$ pathlengths are shown in Fig. 6a for the SSME exhaust plume for $1.420 \times 10^{3} \mathrm{mb}$ water vapor partial pressure in the Mach diamond. Mid-latitude summer model atmosphere has been utilized for concentration of other species. As expected, the total radiance decreases as the pathlength increases because of increased losses due to transmittance. Similar results for $0,0.1$, and $1.0 \mathrm{~m}$ pathlengths are shown in Fig. 6b. Here, the radiance from the most water vapor bands increase with increased pathlengths. This is because of the fact that the atmospheric layer adjacent to the plume is at sufficiently high temperature to contribute additional radiance and the transmittance losses are very small due to small pathlengths. The critical pathlength, the length at which the increased radiance from the $\delta \mathrm{L}$ increase in the pathlength balances out the transmittance losses due to $\delta \mathrm{L}$, is a function of several variables including the temperature and pressure profiles. Furthermore, the critical pathlength is different for different bands of the same specie. Water vapor concentration for results shown above was modeled using a linear concentration profile starting with the CFD predicted values [13] within the three layers representing the SSME plume and decreasing linearly to the default value given by the Mid-latitude summer model atmosphere at 10 $\mathrm{m}$ from the plume. At this time, there are no experimental measurements available for comparison with our results.

We have also studied the effect of increased concentration of $\mathrm{NO}, \mathrm{N}_{2} \mathrm{O}$, and $\mathrm{NO}_{2}$ in the boundary layer and the adjacent atmospheric layer. The radiance results have been obtained for the SSME plume for 2, 5, and $10 \mathrm{~m}$ pathlengths. Each of these species can affect significantly (more than $5 \%$ increase in radiance at the corresponding wavelength) if it is present at sufficiently high number density, i.e. about 1000 times the default value of standard atmospheric concentrations. Several different concentrations were tried for each specie at each pathlength. The radiance values for any of these species at wavelengths corresponding to their bands are complex functions of emitting band or line intensities, temperature of the emitting/absorbing layers along the line of sight, specie number density, pathlength and other species present. MODTRAN code does take into account all these factors elegantly and comprehensively. The results for the parametric study of plume radiance vs. nitrogen oxide concentrations are not shown here for the sake of brevity.

\section{SUMMARY AND RECOMMENDATIONS}

We have implemented the MODTRAN code for the rocket engine exhaust plume radiance and transmittance computations. It has been shown that transmittance losses can be very, very significant in certain situations even for the short pathlengths. In general, transmittance losses can not be neglected for any pathlength of $2 \mathrm{~m}$ or more. We have adapted the MODTRAN code for the engine plume radiance computations. If the plume composition and flowfield parameters such as the temperature and pressure values are known along the line of sight by means of the experimental measurements or (more likely) CFD simulations, one can compute the radiance from any plume with high degree of accuracy at any desired point in space.

Emission and absorption characteristics of several atmospheric and combustion species have been studied in reference to the rocket engine plume environments at SSC. From our point of view, the most important species are $\mathrm{H}_{2} \mathrm{O}$ and $\mathrm{CO}_{2}$. Other species which need to be included in the model are $\mathrm{CO}, \mathrm{N}_{2} \mathrm{O}$, $\mathrm{NO}_{2}, \mathrm{NO}$, and $\mathrm{CH}_{4}$. We have also studied the effect of clouds, rain, and fog on the plume radiance/transmittance. The transmittance losses are severe if any of these occur along the line of sight.

We have neglected the radiance emanating from the engine and the test stand structural materials, some of which are sure to be significant because of high temperatures involved. We have also not modeled the water vapor and other clouds which may be formed near the test stand during the engine firing. Obviously the effect of these vapor clouds can not be ignored if they are present along the line of sight. Currently, MODTRAN is not equipped to take into account these situations. Effect of plume clouds near 


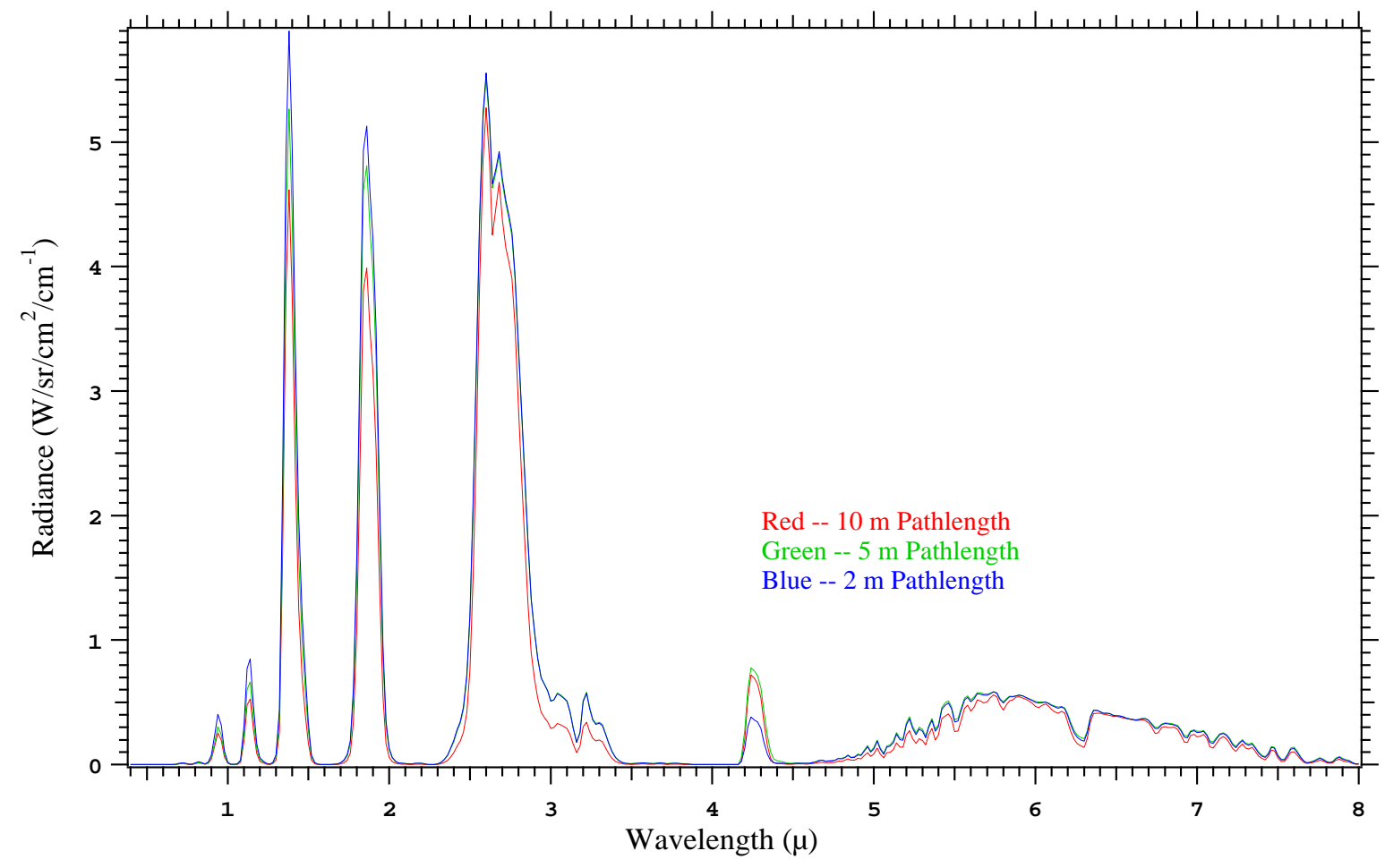

Figure 6a. Total Radiance for 0.4 to $8 \mu$ for the SSME Plume Model for 10, 5, and $2 \mathrm{~m}$ Pathlength Utilizing Mid-Latitude Summer Model Atmosphere.

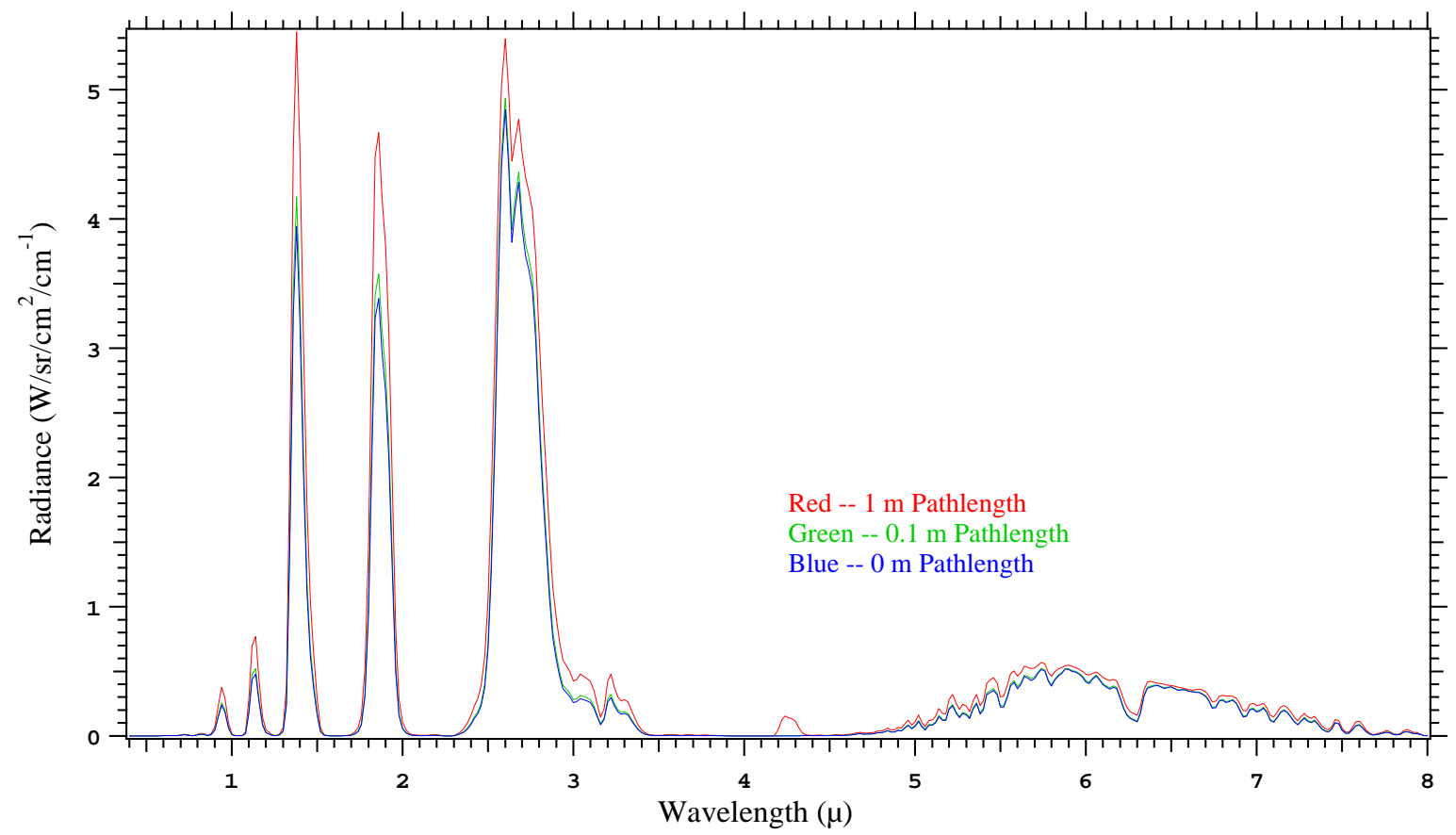

Figure $6 \mathrm{~b}$. Total Radiance for 0.4 to $8 \mu$ for the SSME Plume Model for $1,0.1$, and $0 \mathrm{~m}$ Pathlength Utilizing Mid-Latitude Summer Model Atmosphere. 
the engine test stands needs to be modeled and studied for a better understanding of engine plume radiance/transmittance.

\section{ACKNOWLEDGEMENTS}

The author would like to thank S. Leung for carrying out very diligently hundreds of spectral simulations required for the parametric studies. L. Langford provided his superb expertise with computers during many phases of this work. CFD results were provided by J. West (now at MSFC). The author would also like to thank Dr. West for many stimulating discussions. The author would like to thank W. St. Cyr, R. Daines, and D. Paul Taliancich for reviewing the manuscript and making many useful suggestions. R. Menge did an excellent job in typing this report. Her dedication and patience is appreciated.

\section{REFERENCES}

[1] Kneizys, F. X., Shettle, E. P., Abreu, L. W., Chetwynd, J. H., Anderson, G. P., Gallery, W. O., Selby, J. E. A., and Clough, S. A., Users Guide to LOWTRAN 7, AFGL-TR88-0177, Air Force Geophysics Laboratory, Hanscom AFB, MA. August 16, 1988

[2] Rothman, L. S., Rinsland, C. P., Goldman, A., Massie, S. T., Edwards, D. P., Flaud, J.-M ., Perrin, A., CamyPeyret, C., Dana, V., Mandin, J.-Y., Schroeder, J., McCann, A., Gamache, R. R., Wattson, R. B., Yoshino, K., Chance, K. V., Jucks, K. W., Brown, L. R., Nemtchinov, V., and Varanasi, P., "The HITRAN Molecular Spectroscopic Database and Hawks (HITRAN Atmospheric Workstation): 1996 Edition," Journal of Quantitative Spectroscopy and Radiative Transfer 60 (5), 665, 1998.

[3] Acharya, P. K., Berk, A., Bernstein, L. S., Matthew, M. W., Adler-Golden, S. M., Robertson, D. C., Anderson, G. P., Chetwynd, J. H., Kneizys, F. X., Shettle, E. P., Abreu, L. W., Gallery, W. O., Selby, J. E. A., and Clough, S. A., MODTRAN User's Manual, Version 3.7 and 4.0, Air Force Research Laboratory, Hanscom AFB, MA, December 1, 1998.

[4] Penner, S. S., Quantitative Molecular Spectroscopy and Gas Emissivities, Addison-Wesley, Reading, MA, 1959.

[5] Goody, R. M., Atmospheric Radiation, Theoretical Basis, Oxford University Press, Oxford, Great Britain, 1961. See also, Goody, R. M., and Yung, Y. L., Atmospheric Radiation, Theoretical Basis, Second Edition, Oxford University Press, New York, NY, 1989.

[6] See, for example, Selby, J. E. A., and McClatchey, R. A., Atmospheric Transmittance from 0.25 to $28.5 \mu \mathrm{m}$ : Computer Code LOWTRAN 3, Air Force Cambridge Research Laboratories, Hanscom AFB, MA, May 7, 1975; Kneizys, F. X., Shettle, E. P.,. Gallery, W. O., Chetwynd, Jr., J. H., Abreu, L. W., Selby, J. E. A., Clough, S. A., and Fenn, R. W., Atmospheric Transmittance/Radiance: Computer Code LOWTRAN 6,
Air Force Geophysics Laboratory, Hanscom AFB, MA, August $1,1983$.

[7] See, for example, Tejwani, G. D., "Improved Calculated Linewidths for $\mathrm{H}_{2} \mathrm{O}$ Broadened by $\mathrm{N}_{2}$," Journal of Quantitative Spectroscopy and Radiative Transfer 40 (5), 605 (1988).

[8] Tejwani, G. D., and Varanasi, P., "Approximate Mean Absorption Coefficients in the Spectrum of Water Vapor Between 10 and 22 Microns at Elevated Temperatures," Journal of Quantitative Spectroscopy and Radiative Transfer 10, 373 (1970).

[9] Herzberg, G., Molecular Spectra and Molecular Structure II. Infrared and Raman Spectra of Polyatomic Molecules, D. Van Nostrand Company, Princeton, NJ (1945).

[10] Tejwani, G.D., "Transmittance and Radiance Computations for the SSC Engine Plume Environments," Lockheed Martin Stennis Operations, SSC, MS, October 31, 2002.

[11] Leung, S., "Parametric Study of the Plume Radiance and Atmospheric Transmission Attenuation in Stennis Space Center Environment," National Aeronautics and Space Administration, SSC, MS, August 2, 2002.

[12] Tejwani, G. D., and Thurman, C. C., "Rocket Engine Plume Spectral Simulation and Quantitative Analysis," NASA CP 3282, Vol. I, Advanced Earth-to-Orbit Propulsion Technology, Huntsville, AL, May 17-19, 1994.

[13] West, J., "Plume Properties for Large Throat SSME on the B-1 Test Stand," Lockheed Martin Stennis Operations, SSC, MS, January 27, 1998 (Unpublished Notes). 


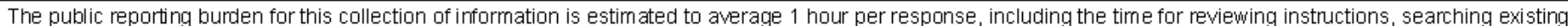

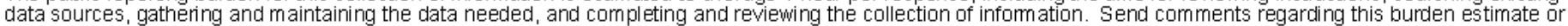

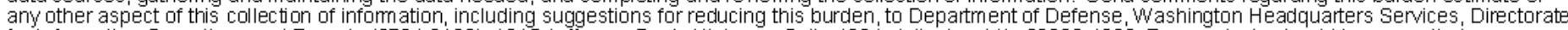
for Information Operations and Reports (0704-0188), 1215 J efferson Davis Highway, Suite 1204, Arlington, VA. 22202-4302. Respondents should be aware that

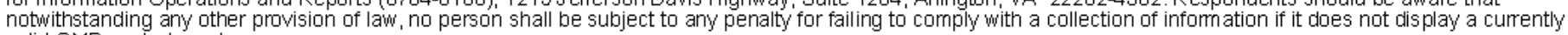
valid OMB control number

PLEASE DO NOT RETURN YOUR FORM TO THE ABOVE ADDRESS.

\begin{tabular}{|l|l|l|}
\hline 1. REPORT DATE (DD-MM-YYYY) & 2. REPORT TYPE & 3. DATES COVERED (FrOM - TO)
\end{tabular}

$$
\text { 24-02-2003 }
$$

4. TITLE AND SUBTITLE

Transmittance and radiance Computations for Rocket Engine Plume

Environment

5a. CONTRACT NUMBER

NAS13-650

5b. GRANT NUMBER

5c. PROGRAM ELEMENT NUMBER

5d. PROJECT NUMBER

6. AUTHOR(S)

Gopal Tejwani 5e. TASK NUMBER

5f. WORK UNIT NUMBER

\section{PERFORMING ORGANIZATION NAME(S) AND ADDRESS(ES)}

Lochkeed Martin Space Operations
8. PERFORMING ORGANIZATION REPORT NUMBER

SE-2003-02-00014-SSC

10. SPONSORINGIMONITOR'S ACRONYM(S)

11. SPONSORING/MONITORING REPORT NUMBER

12. DISTRIBUTIONAVAILABILITY STATEMENT

Publicly Available STI per form 1676

\section{SUPPLEMENTARY NOTES}

Conference- 2003 ASME Summer Heat Transfer Conference Las Vegas, NV July 21 - 232003

\section{ABSTRACT}

Rocket engine exhaust plume is generally thermal in character arising from changes in the internal energy of constituent molecules. Radiation from the plume is attenuated in its passage through the atmosphere. In the visible and the infrared region of the spectrum fo: clear-sky conditions, this is caused mainly through absorption by atmospheric molecular species. The most important

combustion-product molecules giving rise to emission in the IR are water vapor, carbon dioxide, and carbon monoxide. In addition, the high temperature plume reacting with the surrounding atmosphere may produce nitrogen oxides, in the boundary layer, all of which are strongly emitting molecules. Important absorbing species in the atmosphere in the engine plume environment are $\mathrm{H} 2 \mathrm{O}$, $\mathrm{CO}$. $\mathrm{CO} 2, \mathrm{CH} 4, \mathrm{~N} 2 \mathrm{O}, \mathrm{NO}$, and $\mathrm{NO} 2$. Under normal atmospheric conditions, the concentrations of $\mathrm{O} 3, \mathrm{SO} 2$, and $\mathrm{NH} 3$ are too small to produce any significant absorption. Essentially the problem comprises of the propagation of radiation from a hot gas source through a long cool absorbing atmospherethus combining aspects of atmospheric and combustion gas methods. Since many of the same molecular species are responsible for both emission and absorption, the high degree of line position correlation between the emission

15. SUBJECT TERMS

16. SECURITY CLASSIFICATION OF:

\begin{tabular}{|c|c|c|}
\hline a. REPORT & b. ABSTRACT & c. THIS PAGE \\
$\mathrm{U}$ & $\mathrm{U}$ & $\mathrm{U}$ \\
\hline
\end{tabular}

17. LIMITATION OF
ABSTRACT
UU

18. NUMBER PAGES 19b. NAME OF RESPONSIBLE PERSON

Gopal Tejwani

19b. TELEPHONE NUMBER (Include area code)
10 